\title{
Pengaruh Penambahan Unsur Magnesium pada Paduan Aluminium dari Bahan Piston Bekas
}

\author{
Muhammad Abdus Shomad ${ }^{1}$, Aulia Adam Jordianshah ${ }^{2}$ \\ Jurusan Teknologi Mesin Program Vokasi, Universitas Muhammadiyah Yogyakarta \\ Jl. Brawijaya, Tamantirto, Bantul, DI Yogyakarta 55183 \\ e-mail :somach80@gmail.com ${ }^{1}$, auliaadamj@gmail.com ${ }^{2}$
}

\begin{abstract}
ABSTRAK
Secara umum, $70 \%$ berat komponen otomotif terbuat dari bahan aluminium, produk-produk otomotif terbuat dari bahan aluminium yaitu ; piston, blok mesin, kepala silinder, velg dan sebagainya. Dalam penggunaan bahan aluminium pada komponen otomotif, perlu memiliki nilai kekuatan mekanik yang baik. Produk dari bahan logam aluminium dapat dibuat dengan melakukan rekayasa material dengan melakukan campuran paduan seperti: $\mathrm{Cu}, \mathrm{Si}, \mathrm{Mg}, \mathrm{Zn}, \mathrm{Mn}, \mathrm{Ni}$, dan sebagainya. Penelitian ini bertujuan untuk menganalisis tegangan tarik dan modulus elastisitas bahan Al-Si dari bahan piston diesel bekas. Pengujian impak bertujuan untuk menentukan ketangguhan material aplikasi manufaktur swingarm sepeda motor . Proses remelting piston diesel dilakukan peleburan dengan variasi penambahan unsur magnesium $(\mathrm{Mg})$ dengan variasi $0,2,3$, dan 5\%. Peleburan aluminium Al-Si menggunakan cetakan pasir dan membuat spesimen uji dengan standardisasi ASTM-E8M untuk uji tarik dan ASTM-E23 untuk uji impak. Hasil yang diperoleh dalam pengujian tarik dan impak ditujukan untuk memperoleh kekuatan tarik, modulus elastisitas dan keuletan. Optimasi penambahan unsur Mg sebesar 3\% dapat menghasilkan sifat paduan Al-Si yang lebih baik.
\end{abstract}

Kata kunci: Remelting, Piston Diesel, Magnesium (Mg), Swingarm.

\section{Effect of Addition of Magnesium Element to Aluminum Alloy from Used Piston Material}

\section{ABSTRACT}

In general, $70 \%$ by weight of automotive components were made of aluminum, and automotive products are made of aluminum, such as piston, engine block, cylinder head, and alloy wheel. In the use of aluminum materials in automotive components, it is necessary to have a good mechanical strength value. Engineering materials can make aluminum metal products by adding elements such as $\mathrm{Cu}, \mathrm{Si}, \mathrm{Mg}, \mathrm{Zn}, \mathrm{Mn}, \mathrm{Ni}$ in the alloys. This study aims to analyze the tensile stress and elastic modulus of Al-Si material from used diesel piston materials. The impact test aims to determine the material toughness of swingarm motorcycle manufacturing applications. The remelting of the diesel piston process used to add the magnesium $(\mathrm{Mg})$ with variations of 0, 2, 3, and 5\% in the alloy. Casting the Al-Si aluminum uses sand molds and makes test specimens with ASTM-E8M standardization for tensile tests and ASTM-E23 for impact tests. The results obtained in tensile and impact tests were intended to get tensile strength, modulus of elasticity, and tenacity. Optimization of adding 3\% Mg can produce better Al-Si alloy properties

Keywords: Remelting, Piston Diesel, Magnesium (Mg), Swingarm.

\section{Pendahuluan}

Permasalahan yang subtansi dalam pengembangan material adalah menentukan nilai kekuatan mekanis dan sifat fisis pada material apakah sudah optimum agar daya tahan terhadap korosi dan keausan dapat tercapai secara maksimum (Sidharta, 2014). Perkembangan industri bidang material dan metalurgi nasional pun semakin berkembang pesat di Indonesia, sebagai contoh, industri baja nasional pun semakin berkembang dari tahun ke tahun. Pada tahun 2015 saja terdapat peningkatan kapasitas produksi baja nasional hingga 4 juta ton. Ini terus berkembang dari tahun ke tahun dengan dibukanya beberapa pabrik baru seperti PT. Krakatau Posco dan lainnya (Awali dkk, 2018). Industri otomotif mengalami perkembangan yang pesat untuk saat ini sehingga diperlukan komponen yang memiliki sifat fifi dan mekanis untuk mendukung komponen produk kendaraan yang berkualitas (Fauzi, Purwanto, \& Respati, 2016). 
Swingarm merupakan komponen penting pada sepeda motor yang dapat meredam beban kejut dengan baik sehingga kestabilan sepeda motor dapat terjaga. Material yang umumnya digunakan dalam pembuatan swing arm sepeda motor yaitu baja karbon rendah. (Sanjaya, dkk 2015). Material yang saat ini dipakai sering pecah dimungkinkan karena komposisi, perlakuan panas maupun pengerjaan yang salah. Maka dari itu diperlukan adanya penelitian terhadap material yang baik untuk swing arm sepeda motor.

Alumunium paduan telah digunakan lama pada aplikasi-aplikasi tertentu karena memiliki kombinasi sifat mekanis antara lain kekuatan yang tinggi, densitas yang rendah, durabilitas yang baik, kemampuan permesinan yang baik dan biaya yang cukup kompetitif (Kurniawan, F. A., \& Isranuri, I. (2016).

Kebutuhan aluminium di dalam negeri dibagi menjadi dua jenis yaitu virgin dan daur ulang (secondary). Aluminium daur ulang yang dibutuhkan saat ini mencapai 500.000 ton per tahun. Aluminium jenis ini selalu dibutuhkan dipasar domestik saat ini, terutama dibidang otomotif (Andraini, F., Juwanda, F., \& Faozi, S. (2016). Menurut Budinski, (2001) perkembangan pemakaian aluminium pada industri otomotif terus mengalami peningkatan seiring dengan meningkatnya jumlah pemakaian kendaraan bermotor di Indonesia.

Material aluminium banyak digunakan pada kendaraan bermotor seperti diantaranya piston, cylinder block, cylinder head, valve dan velg. Untuk meningkatkan kekuatan fisis dan mekanis material pada umumnya ditambahkan unsur-unsur seperti: $\mathrm{Cu}, \mathrm{Si}, \mathrm{Mg}, \mathrm{Zn}, \mathrm{Mn}, \mathrm{Ni}$, dan sebagainya. Aluminium Selama 50 tahun terakhir ini, telah banyak digunakan tidak hanya pada industry otomotif tetapi juga pada bidang konstruksi dan industri pesawat terbang (Soleh, dkk 2019). Hal ini disebabkan karena karena keunggulan sifat aluminium yaitu ringan, tahan korosi, ulet dan ductile (Irsat dkk, 2018).

Magnesium memiliki sifat antara lain dumping yang baik, massa jenis rendah serta ringan dan kuat apabila dipadukan. Penambahan unsur magnesium dalam konsentrasi tertentu dapat menaikkan nilai kekerasan dan kekuatan tarik pada paduan aluminium (Mizhar \& Fauzi, 2016).

Penelitian ini memanfaatkan bahan daur ulang piston diesel bekas. Pemilihan penggunanan bahan piston diesel bekas didasarkan pada sifat bahan piston diesel yaitu tahan pada suhu tinggi dan memiliki koefisien mui yang sangat kecil. Pembakaran pada ruang bakar silinder liner diperlukan bahan piston yang kuat dan tahan gesek. Piston diesel ini dipegang oleh setang piston yang mendapatkan gerakan turun-naik dari gerakan berputar crankshaft. (Yani, \& Sahbana, 2016).

Piston diesel bekas tersebut dilebur kembali (remelting) dengan proses pengecoran. Hasil pengecoran kemudian dituang dalam media cetakan dapat berupa cetakan pasir ataupun cetakan logam. Modifikasi pengecoran pada umumnya dilakukan pada saluran masuk, saluran keluar, saluran penambah, dan penambahan unsur dalam paduan cor. Tujuan dari modifikasi tersebut untuk mendapat hasil produk jadi yang mempunyai sifat atau karateristik lebih baik (Fasya, \& Iskandar, 2015).

Piston diesel bekas adalah salah satu material daur ulang yang mudah dan banyak persediannya. Penelitian ini bertujuan untuk menganalisis hasil perhitungan pengujian tarik dan impak material paduan remelting piston diesel dengan paduan presentase Magnesium (Mg) 0, 2, 3 dan 5\% serta analisis hasil uji tarik dan impak material ke dalam pengaplikasian beban yang akan diterima oleh swingarm sepeda motor (Alviandra, 2017)

Salah satu cara untuk mengurangi barang bekas atau limbah adalah dengan mendaur ulangnya. Salah satu contoh barang bekas atau limbah yang kita temui dengan jumlah yang banyak dan harga yang relatif rendah adalah aluminium bekas. Dalam proses daur ulangnya dapat ditambahkan unsur paduan atau tambahan untuk menyesuaikan sifat yang diinginkan sehingga daur ulang barang bekas dapat bersaing dengan produk dari aluminium baru (Hadi, Nugroho, Udianto, \& Akbar, 2017). 
Menurut tata surdia (1999) paduan aluminium yang ditambahkan unsur $\mathrm{Mg}$ (Al$\mathrm{Mg}$ ) akan meningkatkan sifat ketanguhan yang baik, daya tahan korosi, kemampuan dituang dan kemampuan dibentuk, sedang paduan aluminium yang ditambahakan unsur slilikon (Al-Si) akan meningkatkan sifat karakteristik material yang hampir sama dengan paduan AlMg (Kurniawan \& Isranuri, 2016).

Penggunaan unsur paduan magnesium $(\mathrm{Mg})$ dapat digunakan pada bahan tambahan almunium pada pembuatan pesawat terbang, komponen-komponen otomotif, penambahan jumlah persentase magnesium yang cukup tinggi mempunyai pengarung sifat mekanis kekuatan karik dan kekerasan yang baik (Nugroho \& Hudawan, 2017).

Proses daur ulang pada bahan material aluminium bekas yaitu dengan melakukan pengecoran logam material tersebut (piston diesel beka)s dimulai dengan melakukan peleburan material sampai pada suhu cair (melting point) kemudian dilanjutkan pada proses penuangan logam cair pada cetakan yang tersedia (Suprapto, 2017).

\section{Metodologi}

Bahan utama yaitu piston diesel bekas yang memiliki komposisi paduan dominan aluminium-silikon. Bahan magnesium yang dicampurkan yaitu 2\%, 3\% dan 5\% seperti terlihat pada Gambar 1 dan Gambar 2.

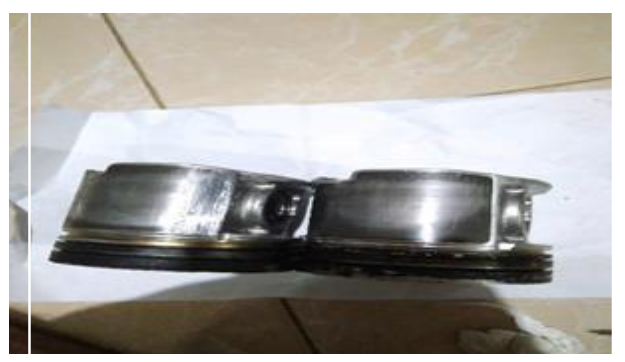

Gambar 1. Piston diesel

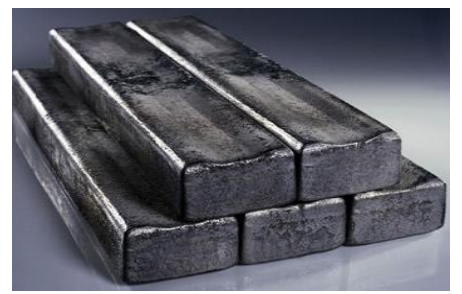

Gambar 2. Logam Magnesium (Mg)

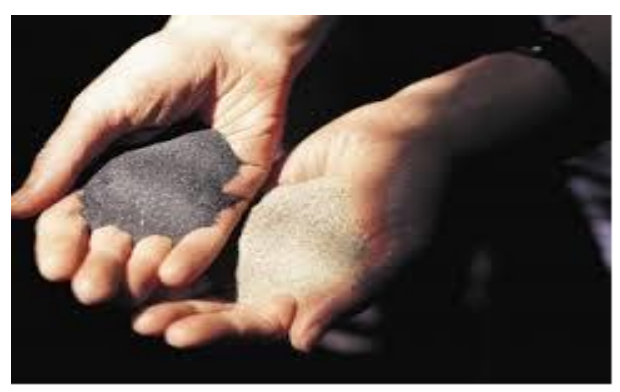

Gambar 3. Pasir Cetak

Pasir cetak (Gambar 3) digunakan membuat cetakan yang juga berfungsi untuk membuat pola/model dan inti, serta menahan aliran cairan logam pada waktu dituangkan kedalam cetakan. Alat utama yang digunakan dalam proses peleburan yaitu tungku (Gambar 4) yang berfungsi sebagai proses dalam peleburan material piston diesel bekas.

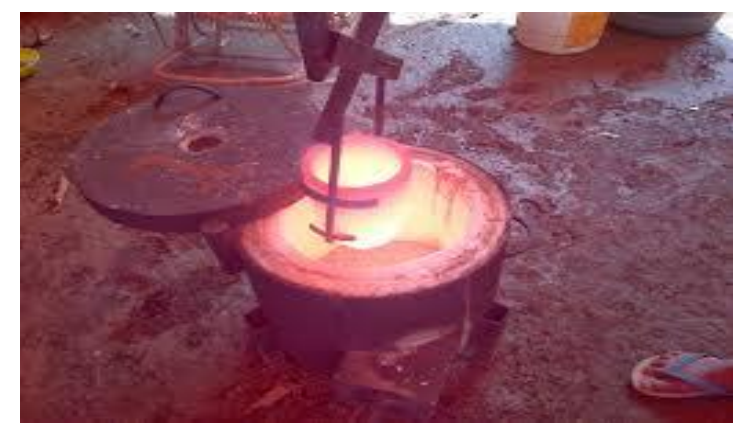

Gambar 4. Tungku Pelebur Logam

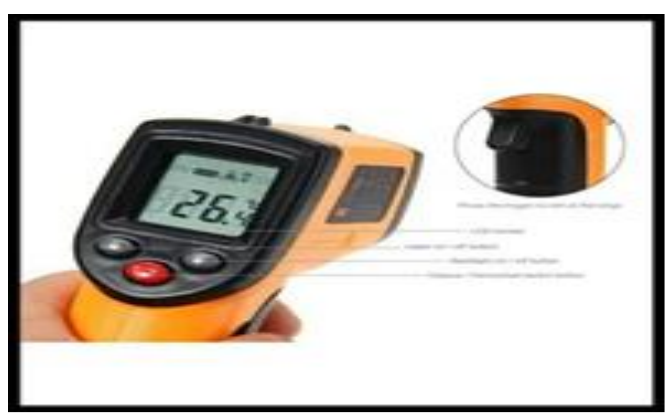

\section{Gambar 5. Termomater Infrared}

Termometer infra merah (Gambar 5) berfungsi untuk mengetahui suhu dalam tungku sehingga dapat diketahui batas titik cair aluminium yang berada pada temperatur $720^{\circ} \mathrm{C}$. 
Adapun langkah dalam proses penelitian dapat dilihat pada diagram alir penelitian (Gambar 6).

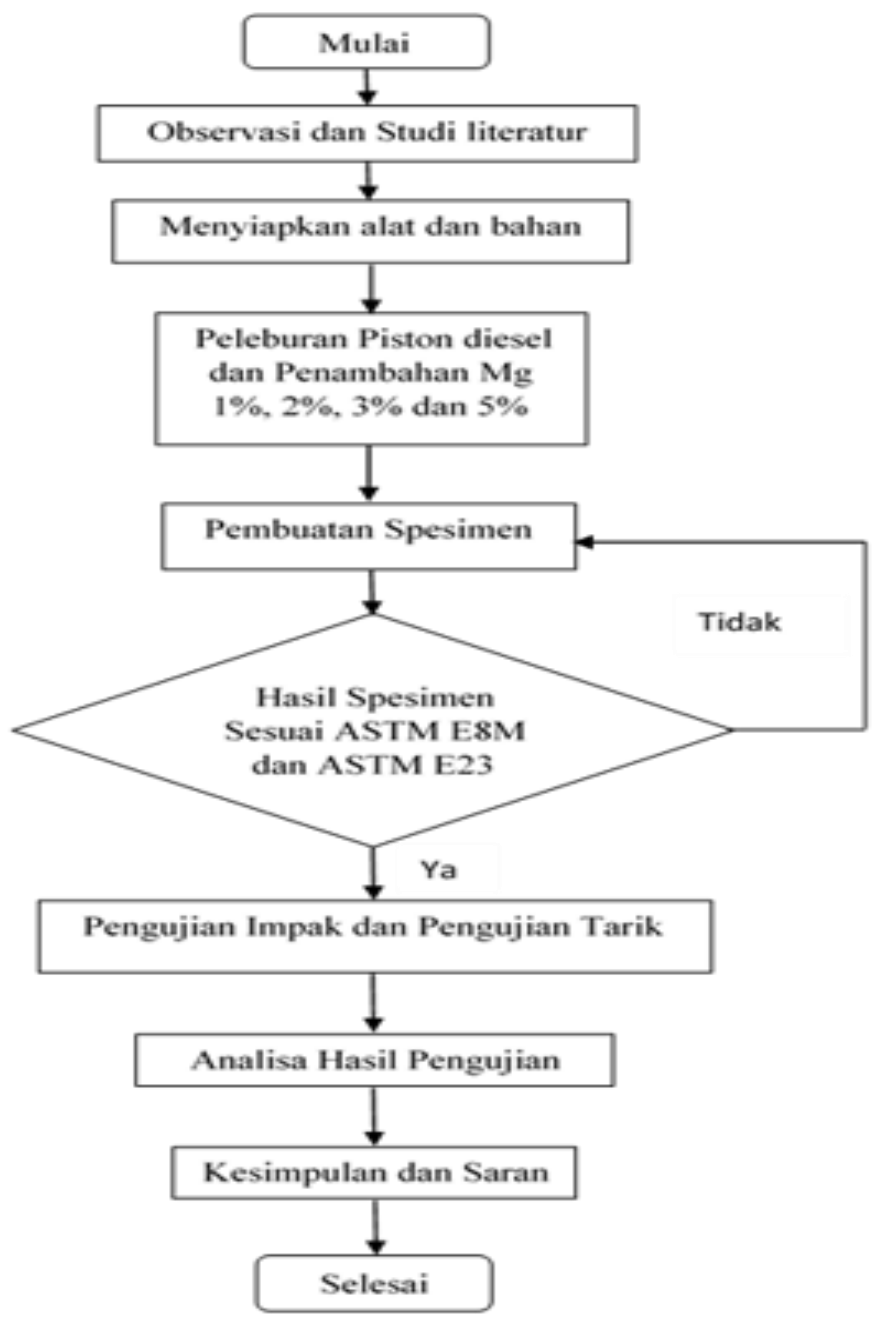

Gambar 6. Diagram Alir Penelitian

Gambar 6 menjelaskan, bahwa di awal penelitian dilakukan studi literatur, yang bertujuan untuk mencari nilai kebaharuan terhadap penelitian sebelumnya yang masih satu tema. Dalam persiapan alat dan bahan, penelitian ini mengunakan bahan material utama yaitu piston bekas yang mempunyai tujuan untuk melakukan daur ulang supaya mengurangi sampah dan memaksimalkan pengolahan kembali sehingga mendapatkan nilai lebih. Dalam proses peleburan, bahan inti yang digunakan yaitu piston bekas dengan penambahan unsur paduan 2\%, 3\% dan 5\% magnesium $(\mathrm{Mg})$.
Pembuatan spesimen dengan menggunakan standar ASTM E 8M (Gambar 7) dan ASTM E 23 (Gambar 8). Untuk langkah pengujian dilakukan dengan pengujian mekanis yaitu pengujian impak dan pengujian tarik. Adapun langkah dalam pengujian mekanis dijelaskan pada bagian Hasil dan Pembahasan. 


\section{Hasil dan Pembahasan}

\subsection{Pengujian Tarik}

Hasil perhitungan pengujian tarik remelting piston dengan penambahan campuran presentase Magnesium (Mg) 2\%, $3 \%$ dan 5\%. Parameter perhitungan persentase Magnesium dari berat paduan aluminium piston bekas yang dilebur seberat 500 gram.



Gambar 7. Spesimen uji ASTM E-8M

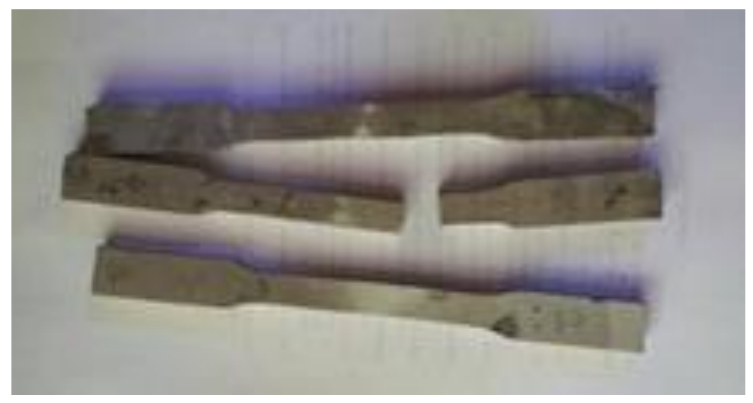

Gambar 8. Bentuk spesimen uji ASTM E8

Berat magnesium yang dilebur yaitu $10 \mathrm{gr}$, 15 gr dan 20 gr.

Pengujian tarik dilakukan di Laboratorium Bahan teknik UGM dan Laboratorium Bahan Politeknik Manufaktur Ceper. Pengujian dilakukan dengan pembebanan 2 Ton. Bentuk spesimen uji sesuai dengan standar ASTM E8M. Spesimen uji dapat dilihat pada Gambar 7 dan Gambar 8. Hasil uji yang didapatkan ditunjukkan pada Gambar 9 dan Gambar 10.

(a)

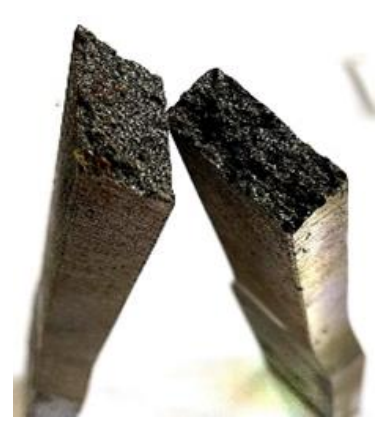

Gambar 9. Bentuk patahan uji tarik dengan penambahan (a) $3 \% \mathrm{Mg}$ dan (b) $5 \%$ (b)






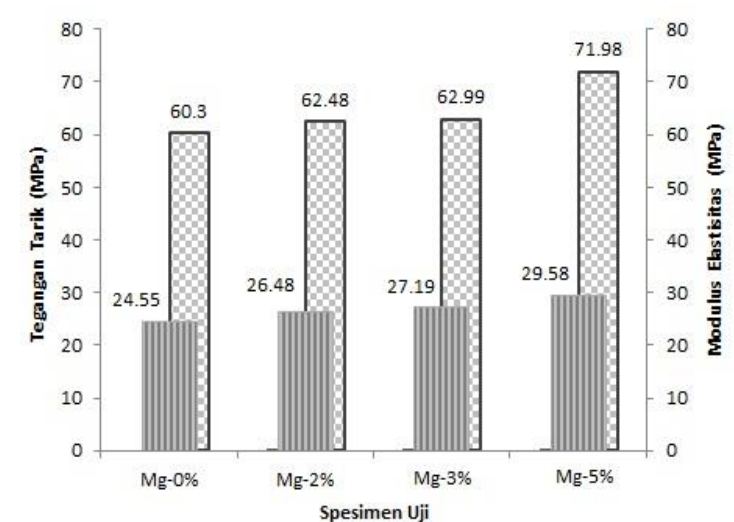

Gambar 10. Hasil uji tarik dan modulus elastisitas paduan Al-Si dengan variasi penambahan magnesium

Gambar 9 (a) menunjukkan patahan uji tarik untuk variasi penambahan $3 \% \mathrm{Mg}$. Penambahan 3\% $\mathrm{Mg}$ ini memperlihatkan warna hitam yang menunjukan patahan ulet. Keuletan bahan paduan aluminium silikon dengan penambahan magnesium bertujuan untuk memperbesar butir sehingga bahan akan semakin ulet.

Gambar 9 (b) menunjukkan patahan uji tarik untuk variasi penambahan $5 \% \mathrm{Mg}$. Penambahan $\mathrm{Mg}$ yang cukup besar mengakibatkan patahan rata dan mengkilap. $\mathrm{Hal}$ ini menunjukkan $\mathrm{Mg}$ mengalami aglomerasi yang menyebabkan besar butir terhambat dalam paduan. Sehingga bahan dengan paduan Al-Si-5\% Mg akan memiliki sifat yang getas.

Gambar 10 menunjukkan grafik hasil nilai kekuatan tarik dan modulus elastisitas paduan Al-Si-Mg. Tegangan tarik terbaik didapat pada penambahan $\mathrm{Mg}$ sebesar 5\% yaitu sebesar 71,98 Mpa. Kekuatan tarik terendah pada AlSi tanpa adanya penambahan unsur $\mathrm{Mg}$ yaitu sebesar 60.3 Mpa. Nilai modulus elastisitas paduan juga meningkat seiring dengan peningkatan nilai kekuatan tarik. Nilai terendah modulus elastisitas diperoleh pada 0\% $\mathrm{Mg}$ (tanpa penambahan unsur paduan) yaitu sebesar 24,55 $\mathrm{MPa}$, sedangakan nilai yang tinggi diperoleh untuk paduan Al-Si sebesar 5\% yaitu 29,58 Mpa.

\subsection{Pengujian Impak}

Pengujian impak charpy menggunakan alat uji yang terdapat di Lab. Bahan teknik UGM. Standarisasi spesimen uji menggunakan standar ASTM E 23 seperti ditunjukkan pada Gambar 11.

Spesimen uji impak memiliki dimensi dengan panjang spesimen $55 \mathrm{~mm}$ dan Panjang span sebesar $32 \mathrm{~mm}$, sehingga spesimen harus dibuat lebih panjang dari panjang ukurannya digunakan sebagai tumpuan. Persamaan mencari nilai keuletan bahan sebagai berikut ;

$\mathrm{E}=\mathrm{G} \cdot \mathrm{R}(\cos \beta-\cos \alpha)$

$\mathrm{I}=\mathrm{E} / \mathrm{A}$

Dengan catatan:

$\mathrm{E}=$ Energi serap benda uji (Joule)

$\mathrm{G}=$ Berat pendulum $(9,5 \mathrm{~kg})$

$\mathrm{R}=$ jarak lengan ayun $(810 \mathrm{~mm})$

$\alpha=$ sudut ayun awal pendulum

$\beta=$ sudut setelah mengenai benda uji

$\mathrm{A}=$ luas penampang patah benda uji $\left(\mathrm{mm}^{2}\right)$

$\mathrm{I}=$ Kekuatan impak $\left(\right.$ Joule $\left./ \mathrm{mm}^{2}\right)$

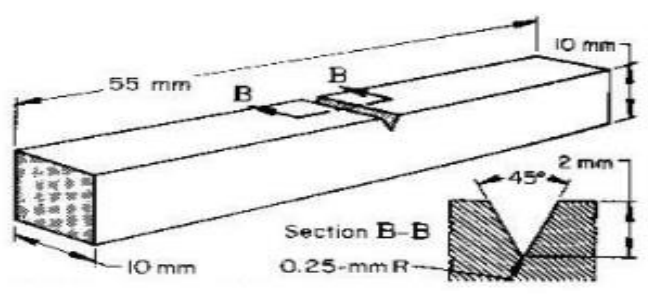

Gambar 11. Dimensi Spesimen Uji Impak 80

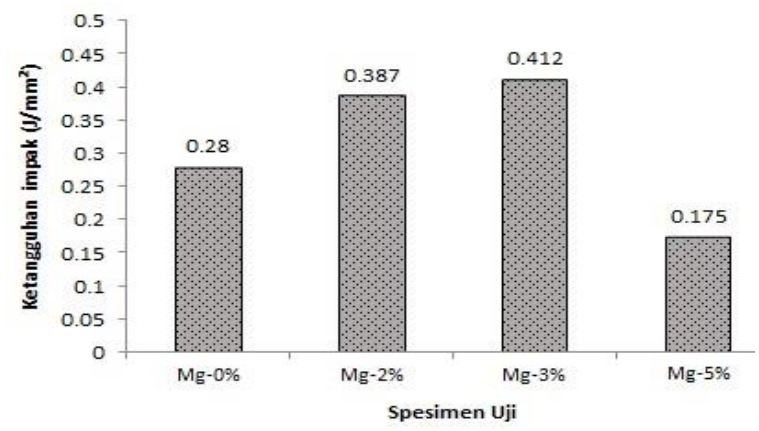

Gambar 12. Hasil Uji Impak 
Kekuatan impak paduan aluminium silikon yang diberi penambah unsur $\mathrm{Mg}$ (magnesium) memberi dampak kenaikan keuletan bahan (Triono, Triyono dan Yaningsih, 2015).

Penambahan unsur Mg optimum untuk menaikan kekuatan ulet paduan ini. Keuletan sebesar 0,28 J/mm $\mathrm{mm}^{2}$ untuk paduan Al-Si tanpa penambahan $\mathrm{Mg}$. Paduan Al-Si dengan penambahan konsentrasi $2 \%$ dan 3\% akan mengakibatkan peningkaatan kekuatan impak sebesar $0,387 \mathrm{~J} / \mathrm{mm}^{2}$ dan $0,412 \mathrm{~J} / \mathrm{mm}^{2}$. Penambahan konsentrasi lebih dari $3 \%$ menyebabkan aglomerasi dan porositas kecil atau chill pada paduan aluminium silikon (Purnawan, Jokosisworo dan Yudo, 2016). Penambahan 5\% Mg juga mengakibatkan paduan aluminium menjadi getas.

\section{Kesimpulan}

Hasil pengaruh penambahan unsur $3 \% \mathrm{Mg}$ pada paduan Al-Si dari bahan piston diesel bekas menghasilkan kekuatan sebesar 62,99 Mpa. Pada pengujian impak menunjukkan bahwa penambahan $\mathrm{Mg}$ optimal pada $3 \%$ yang menghasilkan kekuatan impak sebesar $0,412 \mathrm{~J} / \mathrm{mm}^{2}$. pada $3 \%$ yang menghasilkan kekuatan impak sebesar $0,412 \mathrm{~J} / \mathrm{mm}^{2}$.

\section{Daftar Pustaka}

Alviandra, S. (2017). Pengaruh Penambahan Unsur Paduan Magnesium Pada Al-Si Menggunakan Dapur Krusibel Terhadap Sifat Kekerasan Dan Struktur Mikro. Jurnal Teknik Mesin TRANSMISI, 13(2), 217-226.

Andraini, F., Juwanda, F., \& Faozi, S. (2016). Analisis Hukum Progresif Terhadap Hukum Investasi Dalam Undang-undang No. 25 Tahun 2007 Dan Perjanjian Internasional.

Awali, J., Ismail, I., Aryatama, O., Triana, Y., \& Asih, W. (2018). Pelatihan Daur Ulang Logam (Alumunium) bagi Masyarakat Karang Joang. Jurnal Pengabdian kepada Masyarakat (Indonesian Journal of Community Engagement), 4(1), 1-10.
Budinski, 2001," Engineering Materials Properties and Selection," PHI New Delhi, pp. 517-536.

Fasya, F., \& Iskandar, N. (2015). Melt Loss Dan Porositas Pada Aluminium Hasil Daur Ulang. JURNAL TEKNIK MESIN, 3(1), 44-50.

Fauzi, I., Purwanto, H., \& Respati, S. M. B. (2016). Analisis pengaruh variasi tekanan pada pengecoran squeeze terhadap struktur mikro dan kekerasan produk sepatu kampas rem berbahan aluminium silikon (Al-Si) daur ulang dengan penambahan $0,05 \%$ unsur titanium (Ti). Jurnal Ilmiah Momentum, 12(1).

Hadi, S., Nugroho, R. H., Udianto, P., \& Akbar, A. W. (2017, October). Efek daur ulang aluminium piston sepeda motor terhadap kekuatan tariknya. In Seminar Nasional Teknologi Terapan (MESIN) (Vol. 3, No. 01, pp. 75-82).

Irsat, M. M. (2018). Tingkat Kekuatan Carabiner Dengan Beberapa Bentuk Variasi Dari Bahan Al 6061 Dengan Desain Triangel, Pentagon, Box, Butterfly Wings, Kite (Doctoral Dissertation, Universitas 17 Agustus 1945).

Kurniawan, F. A., \& Isranuri, I. (2016). Penyelidikan Karakteristik Mekanik Tarik Paduan Aluminium Magnesium (Al-Mg) Dengan Metode Pengecoran Konvensional. Jurnal Inotera, 1(1), 1-4.

Mizhar, S., \& Fauzi, R. (2016). Pengaruh Penambahan Magnesium Terhadap Kekerasan, Kekuatan Impak Dan Struktur Mikro Pada Aluminium Paduan (Al-Si) Dengan Metode Lost Foam Casting. Jurnal Ilmiah Teknik Mesin" MEKANIK", $2(2$

Nugroho, E., \& Hudawan, Y. (2017). Pengaruh Variasi Putaran Cetakan Dan Penambahan Inokulan Ti-B Pada Centrifugal Casting Terhadap Sifat Mekanik Dan Struktur Mikro Paduan Aluminium A356. 0. Turbo: Jurnal Program Studi Teknik Mesin, 5(1).

Prabowo, A. S., Triyono, T., \& Yaningsih, I. (2016). Analisa Pengaruh Penambahan Mg Pada Komposit Matrik Aluminium 
Remelting Piston Berpenguat $\mathrm{SiO}_{2}$ Menggunakan Metode Stir Casting Terhadap Kekerasan Dan Densitas. Mekanika, 15(1).

Pranata, M. D. E. (2016). Analisis Struktur Mikro Dan Sifat Mekanik Paduan Al 2014 Hasil Proses Aging Dengan Variasi Temperatur Dan Waktu Tahan. Jurnal Furnace, 1(1).

Purnawan, A., Jokosisworo, S., \& Yudo, H. (2016). Analisa Kekuatan Tarik Dan Komposisi Bahan Paduan Aluminium Limbah Piston Dengan Metode Metal Casting Untuk Bahan Jendela Kapal. Jurnal Teknik Perkapalan, 4(4).

Purkuncoro, A., \& Taufik, A. (2019). Analisis Perbandingan Model Cacat Coran Pada Bahan Besi Cor Dan Aluminium Dengan Variasi Temperatur Tuang Sistem Cetakan Pasir. Industri INOVATIF, 6(1), 38-44.

Sahid, M. N. (2017). Analisis Sifat Fisis Dan Mekanis Hasil Coran Blok Silinder Sepeda Motor Berbahan Piston Bekas Dengan Penambahan 0, 05\% Ti-B. Tugas Akhir, Universitas Muhammadiyah Yogyakarta.

Sanjaya, E. I. (2016). Analisa Uji Tarik Dan Struktur Mikro Pada Hasil Pengecoran Ulang Aluminium (Remelting). Skripsi, Universitas Lampung.

Setyarini, P. H., Suprapto, W., Dyan, K. R. P. (2019). Kekuatan Tarik Dan Porositas Handle Rem Hasil Proses Pengecoran Ulang Material Daur Ulang Piston. Prosiding Seminar Nasional Sains dan Teknologi, Vol 1, No 1, 52-58.

Siswanto, R. (2014). Analisis Pengaruh Temperatur Dan Waktu Peleburan Terhadap Komposisi Al Dan Mg Menggunakan Metode Pengecoran Tuang. In Proceedings Seminar Nasional Teknik Mesin Universitas Trisakti (SNTMUT-2014), Jakarta.
Sudarwanto, A., Darmojo, K. W., \& Suyanto, S. (2017). IbPE Kriya Logam pada Sentra kerajinan Tembaga, Kuningan dan Aluminium di Desa Tumang, Cepogo, Kabupaten Boyolali, Jawa Tengah Laporan Akhir Tahun Program Iptek Bagi Masyarakat.

Suparjo, S. Analisa Sifat Fisis dan Mekanis Pulley Hasil Coran dengan Bahan Tambah Piston Bekas. Teknika Polsri, 32(1).

Suprapto, H. (2017). Metodologi Penelitian untuk Karya Ilmiah. Yogyakarta: Gosyen Publishing.

Supriyadi, A., Surdia, T dan Saito. (1992). Pengetahuan Bahan Teknik. Jakarta: PT Pradnya Paramitha.

Surdia, T. (1999). Saito. S.(992). Pengetahuan Bahan Teknik, Pradnya Paramita. Jakarta.

Smith, F. William. 1995. Material Science and Engineering. (second edition). New York: Mc Graw-Hill Inc.

Soleh, G. D. P. S. (2019). Pengaruh Sifat Fisik Dan Mekanik Hasil Pengecoran Aluminium Silikon Dan Campuran Zn Daur Ulang (Doctoral Dissertation, University Of Muhammadiyah Malang).

Triono, A., Triyono, T., \& Yaningsih, I. (2015). Analisa Pengaruh Penambahan Mg pada Matriks Komposit Aluminium Remelting Piston Berpenguat $\mathrm{SiO}_{2}$ Terhadap Kekuatan Impak dan Struktur Mikro Menggunakan Metode Stir Casting. Mekanika, 14(1).

Yani, A., \& Sahbana, A. (2016). Pengaruh Perlakuan Panas Dengan Air Dan Oli Terhadap Kekuatan Impact (Benturan) Bahan Piston Dan Cylinder Liner. Widya Teknika, 24(1). 